\title{
Extracellular HMGB1 Modulates Glutamate Metabolism Associated with Kainic Acid- Induced Epilepsy-Like Hyperactivity in Primary Rat Neural Cells
}

\author{
Yuji Kaneko ${ }^{a}$ Colleen Pappas ${ }^{b}$ Teresita Malapira ${ }^{a}$ Fernando Ĺ. Vale ${ }^{a}$ Naoki Tajiria \\ Cesar V. Borlongan ${ }^{a}$ \\ aCenter of Excellence for Aging and Brain, Department of Neurosurgery and Brain Repair, University of \\ South Florida College of Medicine, Tampa, 'bSchool of Aging Studies, University of South Florida, Tampa, \\ USA
}

\author{
Key Words \\ Epilepsy $\bullet \mathrm{HMGB1} \cdot$ Kainic acid $\bullet$ Primary rat neural cells $\bullet$ Glutamate $\bullet$ GABA
}

\begin{abstract}
Background/Aims: Neuroinflammatory processes have been implicated in the pathophysiology of seizure/epilepsy. High mobility group box 1 (HMGB1), a non-histone DNA binding protein, behaves like an inflammatory cytokine in response to epileptogenic insults. Kainic acid (KA) is an excitotoxic reagent commonly used to induce epilepsy in rodents. However, the molecular mechanism by which KA-induced HMGB1 affords the initiation of epilepsy, especially the role of extracellular HMGB1 in neurotransmitter expression, remains to be elucidated. Methods: Experimental early stage of epilepsy-related hyperexcitability was induced in primary rat neural cells (PRNCs) by KA administration. We measured the localization of HMGB1, cell viability, mitochondrial activity, and expression level of glutamate metabolism-associated enzymes. Results: KA induced the translocation of HMGB1 from nucleus to cytosol, and its release from the neural cells. The translocation is associated with post-translational modifications. An increase in extracellular HMGB1 decreased PRNC cell viability and mitochondrial activity, downregulated expression of glutamate decarboxylase67 (GAD67) and glutamate dehydrogenase (GLUD1/2), and increased intracellular glutamate concentration and major histocompatibility complex II (MHC II) level. Conclusions: That a surge in extracellular HMGB1 approximated seizure initiation suggests a key pathophysiological contribution of HMGB1 to the onset of epilepsy-related hyperexcitability.
\end{abstract}




\section{Introduction}

Epilepsy is a debilitating neurological disorder affecting approximately $2 \%$ of the world's population. Over three million Americans suffer from some form of epilepsy, with mesial temporal lobe epilepsy (TLE) being the most common, arising from the temporal lobe structures of amygdala, hippocampus, and parahippocampal gyrus [1]. Despite the availability of many antiepileptic drugs (AEDs), greater than $30 \%$ of TLE patients will have seizures refractory to standard therapeutics, highlighting the need for more effective therapies [2].

High mobility group box 1 (HMGB1) belongs to a damage-associated-molecular-patterns (DMAP) family [3], is a highly conserved non-histone nuclear protein, and contributes to the architecture of chromatin DNA [4]. HMGB1 is a promiscuous sensor driving a pathogenic inflammatory mediator such as septic shock $[5,6]$, ischemia [7-10], traumatic brain injury [11], epilepsy [12], Parkinson's disease [13], Alzheimer's disease [14], pancreatitis [15], and other neurodegenerative disorder diseases [16]. HMGB1 induces inflammation mainly through receptor for advanced glycation end products (RAGE) and Toll-like receptor 4 [12, 17-19].

Unilateral injection of kainic acid (KA), an agonist to the excitatory neurotransmitter glutamate, into the rodent brain induces epileptic seizures, and granule cell dispersion [20]. Seizures are the results of an imbalance between excitatory and inhibitory neuronal activities. Increased glutamate release into synaptic clefts, in part, leads to excitotoxic lesion-induced epilepsy. KA promotes neurotoxicity involving epileptogenic effects via the $\alpha$-amino-3-hydroxy-5-methyl-4-isoxazolepropionic acid and kainate receptors in modulating the neurotransmitter glutamate [21]. A high concentration of glutamate, resulting from hyperexcitation of the neuronal network, is thought to play a key role in the initiation and spread of seizures. Interestingly, KA has been reported to induce seizures in animals coincident with a significant increment in HMGB1 concentration in the hippocampus [22]. Although HMGB1 translocation has been shown to be tightly regulated by post-translation modifications, in particular altered expression of glutamate metabolism-associated enzymes, such molecular mechanism underlying KA-induced HMGB1 upregulation remains unexplored.

In this study, using our recently reported cell culture model of early stage epilepsyrelated hyperexcitability involving KA treatment of primary rat neural cells (PRNCs) [23], we examined HMGB1 translocation (nuclear to cytosol to extracellular space) and the expression levels of glutamate metabolism-associated enzymes. The present results demonstrated that aberrant extracellular HMGB1 may contribute to the disease pathophysiology of epilepsyrelated hyperexcitability.

\section{Materials and Methods}

\section{Cell culture}

Primary rat neural cells (PRNCs) were obtained from BrainBit (E18 rat cortex) and grown in culture as we previously reported [24]. Cells $\left(4 \times 10^{4}\right.$ cells/well) were suspended in $200 \mu$ l Neural Medium (NbActive 4, BrainBit NB4-500) containing $2 \mathrm{mM} \mathrm{l}$-glutamine and 2\% B27 in the absence of antibiotics and grown in poly-l-lysine-coated 96 -well plates (BD 354516 ) at $37^{\circ} \mathrm{C}$ in humidified atmosphere containing $5 \% \mathrm{CO}_{2}$. We were able to consistently grow PRNCs consisting of 40\% neurons and 60\% astrocytes [24]. After 3 days in culture, approximately $60 \%$ cell confluence was achieved. Next, PRNCs ( $8 \times 10^{4}$ cell/well) were cultured in $400 \mu \mathrm{l}$ neural medium containing $2 \mathrm{mM} l$ - glutamine and $2 \%$ B27 in the absence of antibiotics in poly-llysine 8-chamber (BD 354632) for 3 days at $37^{\circ} \mathrm{C}$. Thereafter, the cells were exposed to $10 \mu \mathrm{M} \mathrm{KA}$ alone, 1 $\mu \mathrm{g} / \mathrm{ml}$ HMGB1 (Chimerigen Laboratories, NP 0370951.1), $10 \mu \mathrm{M}$ KA in the presence of $1 \mu \mathrm{g} / \mathrm{ml}$ HMGB1, 1 $\mu \mathrm{g} / \mathrm{ml} \mathrm{HMGB1}$ in the presence of $1 \mu \mathrm{g} / \mathrm{ml}$ anti HMGB1 antibody, or in the absence of reagent (control) for 3 days at $37^{\circ} \mathrm{C}$.

\section{KARGER}




\section{Cellular Physiology Cell Physiol Biochem 2017;41:947-959

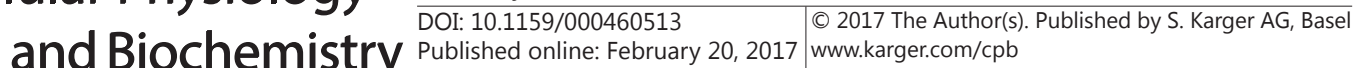 \\ Kaneko et al.: HMGB1 and Epilepsy-Like Hyperactivity}

Immunocytochemistry

Following treatments mentioned above, PRNCs were fixed in 4\% paraformaldehyde [24]. The cells were washed 5 times for $10 \mathrm{~min}$ in phosphate saline buffer (PBS) containing 0.1\% Tween-20 (PBST), and then were blocked by 5\% normal goat serum (Invitrogen 50062Z) in PBST for $1 \mathrm{~h}$ at room temperature (RT). Primary antibodies, anti-HMGB1 rabbit monoclonal antibody (Abcam, ab79823, 1/500) and antimicrotubule-associated protein 2 (MAP2) mouse monoclonal antibody (Abcam, ab11267, 1/10,000) were used. The cells were incubated overnight at $4^{\circ} \mathrm{C}$ with primary antibody with $5 \%$ normal goat serum. The cells were washed 5 times for 10 min in PBST and then soaked in 5\% normal goat serum in PBST containing corresponding secondary antibodies, goat anti-rabbit IgG-Alexa 488 (green, Invitrogen A11008, 1/1,000) and goat anti-mouse IgG-Alexa 594 (red, Invitrogen A11005, 1/1,000) for 90 min in dark. Finally, cells were washed 5 times for $10 \mathrm{~min}$ in PBST and 3 times for $5 \mathrm{~min}$ in PBS, then processed for Hoechst 33258 (Sigma B2883) for $30 \mathrm{~min}$, washed in PBS, and cover-slipped with Fluoromount. Immunofluorescent images were visualized using confocal microscope (Olympus FV1000). Control experiments were performed with the omission of the primary antibodies yielding negative results. HMGB1 translocation from nucleus to cytosol fraction was assessed by measuring the area of the cells with visible cytoplasmic HMGB1 staining from at least five randomly selected microscopies field (400x, cell count approximately 50) using ImageJ [23].

\section{Measurement of extracellular HMGB1 concentration}

After PRNC treatments as detailed above, the culture medium was centrifuged at $3000 \mathrm{~g}, 4^{\circ} \mathrm{C}$ for 15 min, and the supernatant was processed for HMGB1 expression using ELISA kit (amin416082, Antibody, Atlanta, GA, USA) and measured the absorbance at $450 \mathrm{~nm}$ on a Synergy HT plate reader (Bio-Tex).

\section{Measurement of cell viability}

Measurement of cell viability was performed by both fluorescent live/dead cell assay and trypan blue exclusion method [25]. A two-color fluorescence cell viability assay was performed by calcein acetoxymethyl ester (calcein-AM, Invitrogen C3099) to be retained within live cells, including an intense uniform green fluorescence and ethidium homodimer (EthD-1) to bind the nuclei of damaged cells. Following treatments as noted above, PRNCs were incubated with $2 \mu \mathrm{M}$ calcein-AM and $4 \mu \mathrm{M}$ EthD-1 for 45 min at RT in dark. After washing once with phosphate buffer saline, PBS, (Sigma-Aldrich P-3813), the green fluorescence of the live cells was measured by the Gemini EX florescence plate reader (Molecular Device), excitation at 490 $\mathrm{nm}$ and emission at $520 \mathrm{~nm}$. In addition, trypan blue (Gibco, 15250, 0.4\%) exclusion method was conducted and mean viable cell counts were calculated in 4 randomly selected areas $\left(1 \mathrm{~mm}^{2}, \mathrm{n}=10\right)$ to reveal the cell viability. Briefly, within 5 min after adding trypan blue, we digitally captured under microscope (200x) 10 pictures (approximately 100 cells/picture) for each condition, then randomly selected 5 pictures, and counted the number of cells for each individual treatment condition. Normalized cell viability was calculated from the following equation: viable cells $(\%)=[1.00-($ Number of blue cells $/$ Number of total cells $)] \times 100$. To precisely calibrate the cell viability, the values were standardized from florescence intensity and trypan blue data [24].

Measurement of mitochondrial activity

Following PRNC treatments as detailed above, reduction of 3-(4,5-dimethyl-2-thiazoyl)-2,5diphenyltetrazolium bromide (MTT) (Roche 11465007001) by mitochondrial dehydrogenases [24] and WST-1 (4-[3(4-lodophenyl)-2-(4-nirtophenyl)-2H-5-tetrazolio]-1,3-benzene disulfonate; 05015944001, Roche) by mitochondrial succinate tetrazolium reductase were used as a measure of mitochondrial activity as previously described [26], respectively. Briefly, the cells were treated with $0.5 \mathrm{mg} / \mathrm{ml}$ MTT solution at $37^{\circ} \mathrm{C}$ for $4 \mathrm{~h}$, and subsequently incubated with lysis buffer for $14 \mathrm{~h}$ in the incubator in a humidified atmosphere at $37^{\circ} \mathrm{C}$ and $5 \% \mathrm{CO}_{2}$. The optical density of solubilized purple forzmazan was measured at $570 \mathrm{~nm}$ on a Synergy HT plate reader (Bio-Tex). The cells were treated with $10 \mu \mathrm{l}$ WST-1 solution at $37^{\circ} \mathrm{C}$ for $4 \mathrm{~h}$, and subsequently, and measured absorbance at $450 \mathrm{~nm}$.

\section{Western blot analysis}

After PRNC treatments as above, the cells were treated with CelLytic MT mammalian lysis reagent (Sigma-Aldrich, C3228) with protease inhibitor cocktail (Sigma-Aldrich, I3786). The lysate was centrifuged at $3,000 \mathrm{~g}$ and $4^{\circ} \mathrm{C}$ for $15 \mathrm{~min}$, and the supernatant was stored at $-80^{\circ} \mathrm{C}$ until used. Protein samples $(5 \sim 30$ 


\section{Cellular Physiology Cell Physiol Biochem 2017;41:947-959 \begin{tabular}{cc|c|c|} 
DOI: 10.1159/000460513 & O 2017 The Author(s). Published by S. Karger AG, Basel \\
www.karger.com/cpb
\end{tabular} \\ Kaneko et al.: HMGB1 and Epilepsy-Like Hyperactivity}

$\mu \mathrm{g} / \mathrm{lane}$ ) were run on $12 \%$ Tris-Glycine SDS-PAGE gel [27] and then transferred onto a nitrocellulose membrane (Bio-Rad, 162-0112) at $30 \mathrm{~V}, 4^{\circ} \mathrm{C}$ for $14 \mathrm{~h}$. The nitrocellulose membranes were treated with PBST and 5\% non-fat milk (Bio-Rad, 170-6404) for $45 \mathrm{~min}$ at RT. Membranes were then incubated with the primary antibodies, anti-glutamate decarboxylase67 (GAD67) mouse monoclonal antibody (Abcam, ab26116, 1/1,000), anti-GAD65 mouse monoclonal antibody (Abcam, ab26113, 1/1,000), anti-glutamate dehydrogenase (GLUD1/2) goat polyclonal antibody (Abcam, ab99470, 1/1,000), anti-glutamine synthetase (GS) rabbit polyclonal antibody (Abcam, ab49873, 1/5,000), anti-glutaminase (GLS1/2) rabbit monoclonal antibody (Abcam, ab156876, 1/1,000), anti-HMGB1 rabbit polyclonal antibody (Abcam, ab18256, 1/5,000), and anti-glyceraldehyde-3-phosphate-dehydrogenase (GAPDH) [6C5] mouse antibody (Abcam, ab8245, $1 / 5,000)$ at $4^{\circ} \mathrm{C}$ for $14 \mathrm{~h}$. After washing with PBST, the nitrocellulose membrane was incubated with donkey anti-mouse IRDye800 ${ }^{\circledR} \mathrm{CW}$ secondary antibody (LI-COR 926-32212, 1/5,000) or donkey anti-rabbit IRDye800 ${ }^{\circledR} \mathrm{CW}$ secondary antibody (LI-COR 926-32213, 1/5,000) for $90 \mathrm{~min}$ at RT in dark. Immunoreactive detection using near-infrared fluorescence was performed according to protocol of Odyssey ${ }^{\circledast}$ Infrared Imaging System ( $\mathrm{LI}-\mathrm{COR}^{\circledR}$ ). The relative band intensity was quantified by using NIH image 1.59 software to determine expression level.

\section{Immunoprecipitation (IP) assays}

IP assays were performed according to the manufacturer's protocol supplied for Co-IP Kit (Thermo Scientific, 26149). PRNC whole cell lysate $(500 \mu \mathrm{g} / 100 \mu \mathrm{l}$ PBS containing with protease inhibitors (SigmaAldrich, I3786)) was interacted with anti-HMGB1 rabbit polyclonal antibody (Abcam, ab18256) with beads at $4^{\circ} \mathrm{C}$ for $16 \mathrm{~h}$. Following antibody-beads complexes were treated with elution buffer, immune complexes were recovered by heating the samples at $95^{\circ} \mathrm{C}$ for $5 \mathrm{~min}$ in Laemmli SDS lysis buffer (Bioland Scientific LLC, SAB02-01). Immunoblotting (IB) analysis performed with anti-acetyl-Lysine monoclonal antibody (Millipore, 05-515, 1/500), anti-phospho-Ser/Thr/Tyr mouse monoclonal antibody (Antibody, ABIN300088, 1/50), anti-ubiquitin mouse monoclonal antibody (Abcam, ab7254,1/500), and anti-carbonyl rabbit polyclonal antibody (Cell Biolab Inc., STA-308, 1/1,000).

\section{Measurement of glutamate- and major histocompatibility complex II (MHC II)-concentration}

Conditioned samples from each experimental condition were processed for measurements of glutamate concentration and MHC II concentration following the manufacturer's protocols for glutamate ELISA kit (Novus, KA1909) and the rat MHC II class ELISA kit (ABIN, 812198, CD74), respectively.

\section{Data analysis}

Data were evaluated using one-way analysis of variance (ANOVA) followed by post hoc compromised $\mathrm{t}$-tests. Statistical significance was preset at $\mathrm{p}<0.05$. Data are represented as means $\pm \mathrm{SD}$ from $3 \sim 6$ replicates of each treatment condition.

\section{Results}

\section{Translocation of HMGB1}

We have shown previously that PRNCs viability and mitochondrial activity were significantly decreased in a dose-dependent manner with KA administration, which is an excitotoxic reagent commonly used to induce epilepsy [23]. Here, we observed that following incubation of PRNCs in $10 \mu \mathrm{M}$ KA for 3 days at $37^{\circ} \mathrm{C}$, HMGB1 translocated from nuclei to cytosol (Fig. 1A, yellow arrows, and Fig. 1B) and to extracellular space (Fig. 1C), although the majority of HMGB1 protein remained in the nuclear region (cytosol HMGB1; $19.5 \pm 10.2 \%$, p $<0.05$ ). These results were consistent with previous report [28], and suggested that HMGB1 released from nucleus is capable of inducing signal transduction. Moreover, using MAP2 to label neurons, and non-MAP2 positive stains to mark non-neuronal cells (i.e., astrocytes), HMGB1 translocation from the nucleus to the cytosol was comparable between neurons and astrocytes in the present mixed cell culture paradigm. 


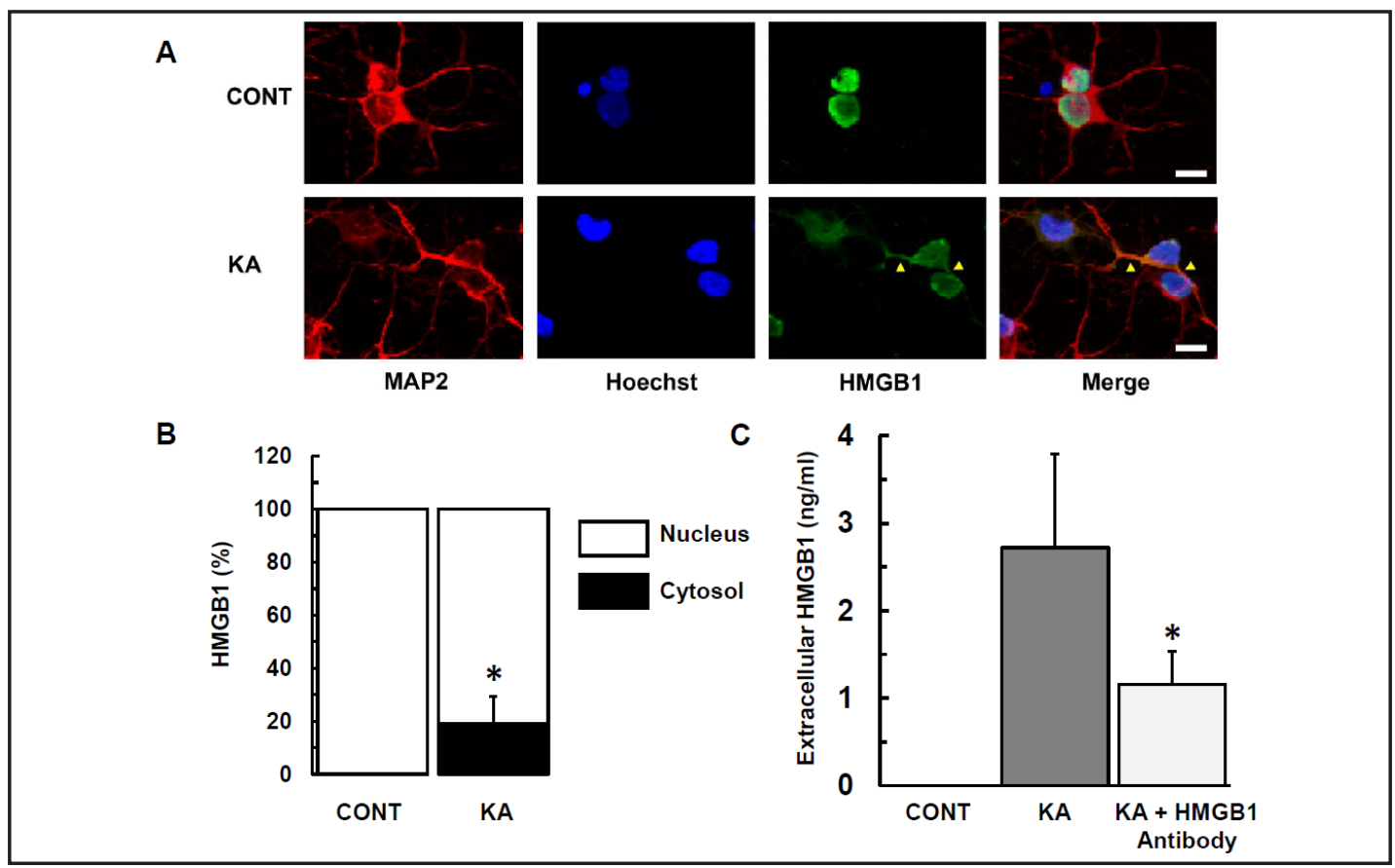

Fig. 1. KA-induced HMGB1 translocation. (A) HMGB1 translocated from the nucleus to the cytosol fraction (yellow arrows) in response to KA (bottom panel comparison with top panel). PRNCs were cultured with $10 \mu \mathrm{M} \mathrm{KA}(\mathrm{KA})$ or in the absence of KA (CONT) for 3 days $37^{\circ} \mathrm{C}$ and stained for neuron (MAP2, red), nucleus (blue, Hoechst), and HMGB1 (green). Scale bars $=5 \mu \mathrm{m}$. (B) Quantification of HMGB1 translocation into cytosol fraction. (C) Measurement of extracellular HMGB1 concentration incubated with $10 \mu \mathrm{M}$ KA (KA), 10 $\mu \mathrm{M} \mathrm{KA}$ and $10 \mu \mathrm{g} / \mathrm{ml}$ anti HMGB1 antibody (KA + Antibody), or with the absence reagent (CONT) for 3 days $37^{\circ} \mathrm{C} . * \mathrm{p}<0.05$.

Fig. 2. KA induced-HMB1 post translation modification. After cultured PRNCs were incubated with $10 \mu \mathrm{M}$ KA (KA) or in the absence of KA (CONT) for 3 days at $37^{\circ} \mathrm{C}$, IP analysis (right panel) using antiHMGB1 antibody directed at acetylation, phosphorylation, ubiquitination, but not carbonylation. Left panel shows the Western blot analysis of HMGB1. Each rectangles' top and bottom line indicated the molecular weight of $40 \mathrm{kDa}$ and $20 \mathrm{kDa}$, respectively. Experiments were independently conducted for 3 times.

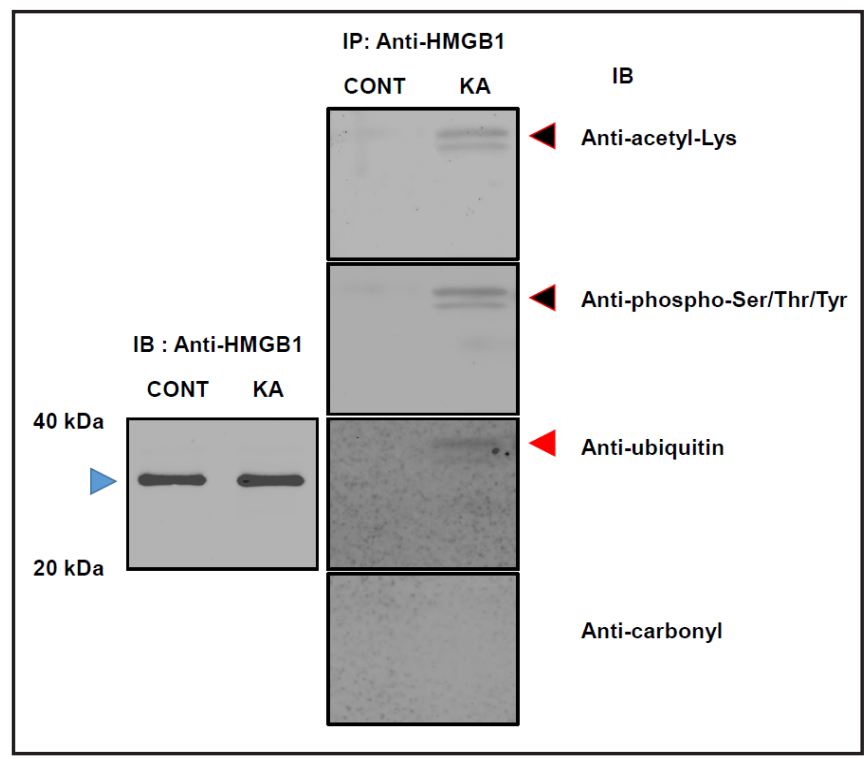

Protein modification of HMGB1

Post-translational modification has been demonstrated to exert a pivotal role for the translocation of HMGB1 [6, 28-32], therefore, we sought to determine whether KA treatment in PRNCs triggered HMGB1 post-translational modification. Immunoprecipitation (IP) analysis demonstrated that HMGB1 was acetylated (Fig. 2 right panel, black arrow), phosphorylated (Fig. 2 right panel, black arrow), and, interestingly, ubiquitinated (Fig. 2 
Fig. 3. Effects of KA and HMGB1 on cell viability and relative mitochondrial activity. After cultured PRNCs were incubated with 10 $\mu \mathrm{M}$ KA (KA), $10 \mu \mathrm{M}$ KA and $1 \mu \mathrm{g} / \mathrm{ml}$ HMGB1 (KA + HMGB1), $1 \mu \mathrm{g} / \mathrm{ml} \mathrm{HMGB1} \mathrm{(HMGB1),}$ $1 \mu \mathrm{g} / \mathrm{ml} \mathrm{HMGB} 1$ and $10 \mu \mathrm{g} / \mathrm{ml}$ anti HMGB1 antibody (HMGB1 + Antibody), or in the absence of reagent (CONT) for 3 days at $37^{\circ} \mathrm{C}$, cell viability and mitochondrial activity were measured by using calcein assay (A), MTT assay (B), and WST-1 assay (C), respectively. $a$ vs $a \mathrm{p}<0.01, b$ vs $b \mathrm{p}<0.001, c$ vs $c \mathrm{p}<0.001, * \mathrm{p}<0.05$, ** $\mathrm{p}<0.01$, and $* * *$ $\mathrm{p}<0.001$. Experiments were independently conducted for 4 or 5 times.

right panel, red arrow), and showed two bands which suggested multiple steps of protein modification [33]. These observations suggested that post-translational modifications after KA treatment caused HMGB1 to dissociate from chromatin DNA, and promoted the release of HMGB1 into the extracellular milieu (Fig. 1C).

Extracellular HMGB1 alters cell viability and mitochondrial activity

We evaluated whether extracellular HMGB1 affected cell viability and mitochondrial activity of PRNCs. Following incubation of PRNCs in $1 \mu \mathrm{g} / \mathrm{ml} \mathrm{HMGB} 1$ for 3 days at $37^{\circ} \mathrm{C}$, cell viability and mitochondrial activity were significantly decreased

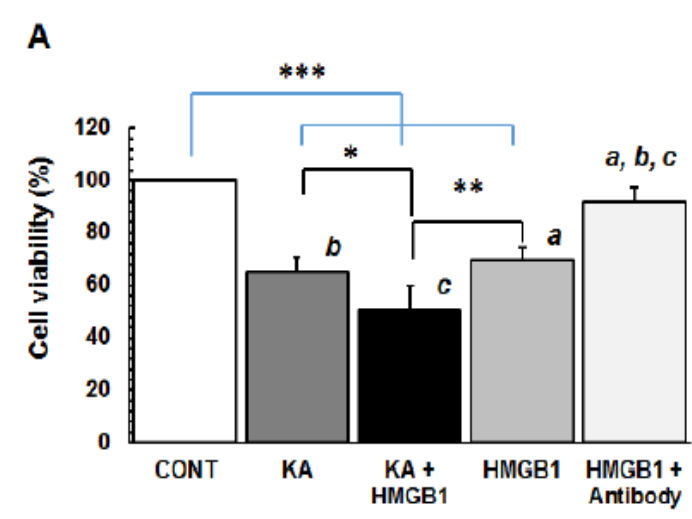

B
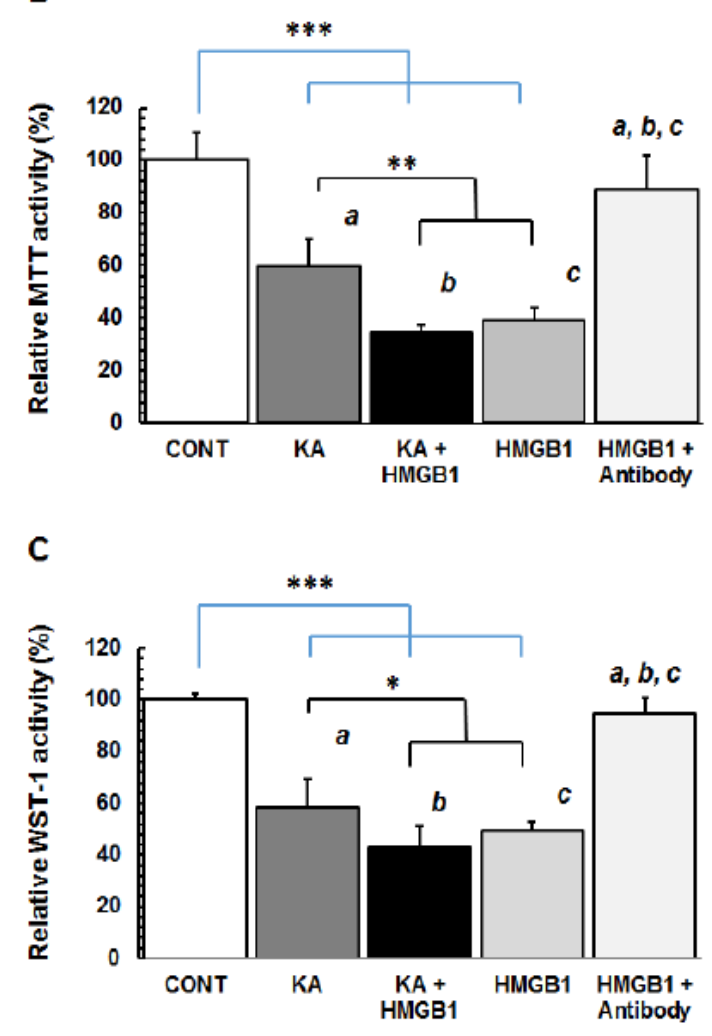

(p's < 0.001; Fig. 3). After co-treatment with $1 \mu \mathrm{g} / \mathrm{ml} \mathrm{HMGB1}$ and $10 \mu \mathrm{g} / \mathrm{ml}$ anti-HMGB1 antibody (Abcam, ab79823), both cell viability $\left(F_{2,16}=58.04, \mathrm{p}<0.0001\right)$ and MTT activity $\left(F_{2,12}=53.5, \mathrm{p}<0.0001\right)$, and WST- 1 activity $\left(F_{2,12}=64.82, \mathrm{p}<0.0001\right)$ were significantly recovered compared with HMGB1 alone. Interestingly, mitochondrial activity was more vulnerable to HMGB1 than KA (Fig. 3B, p < 0.01 and Fig. 3C, p < 0.05).

Extracellular HMGB1 downregulates expression levels of glutamate metabolismassociated enzymes

Initiation of epilepsy is generally viewed as resulting from an imbalanced excitatory/ inhibitory equilibrium, where an excitatory transmitter is glutamate and an inhibitory transmitter is $\gamma$-aminobutyric acid (GABA). We examined whether HMGB1 altered the expression level of glutamate metabolism-associated enzymes in epilepsy-related hyperexcitability (Fig. 4A). Following incubation of PRNCs with $1 \mu \mathrm{g} / \mathrm{ml} \mathrm{HMGB1}$ for 3 days at $37^{\circ} \mathrm{C}$, the expression levels of GAD67 and GLUD1/2, but not GAD65, were significantly decreased (p's < 0.001; Fig. 4B and C). Accordingly, HMGB1-exposed PRNCs shifted the 
A

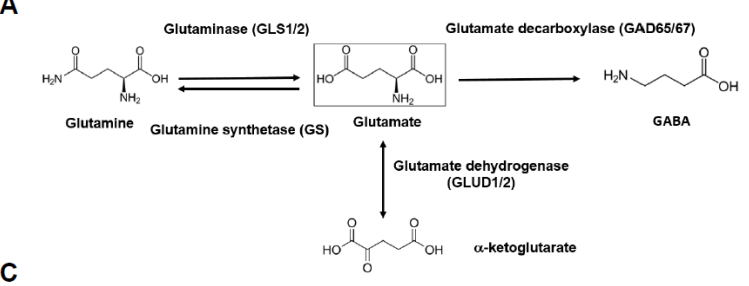

C
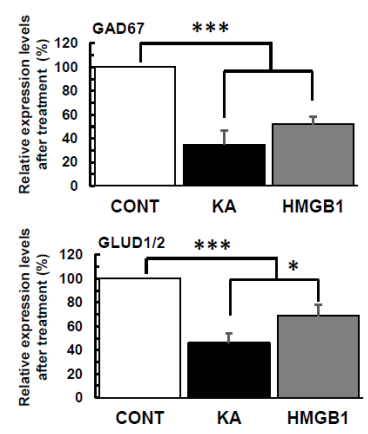

B
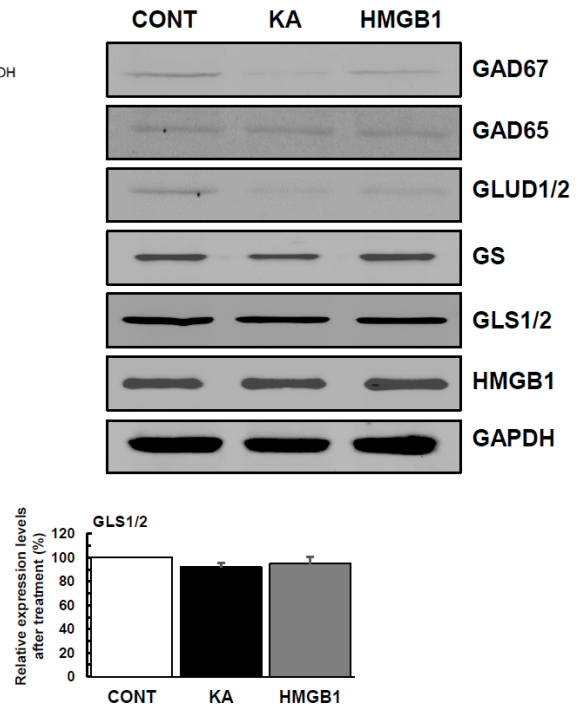

Fig. 4. KA and HMGB1 alter expression of glutamate metabolism-associated enzymes. PRNCs were incubated with $10 \mu \mathrm{M}$ KA (KA), $1 \mu \mathrm{g} / \mathrm{ml}$ HMGB1 (HMGB1), or in the absence of reagent (CONT) for 3 days at $37^{\circ} \mathrm{C}$. (A) Schematic diagram details glutamate metabolism-associated enzymes. (B) Western blotting analysis of glutamate metabolism-associated enzyme expression in PRNCs. (C) Relative quantification of protein expression levels. Experiments were independently conducted for 3 or 4 times. ${ }^{*} \mathrm{p}<0.05,{ }^{* *} \mathrm{p}<0.01$, and $* * * \mathrm{p}<0.001$.

expression level of glutamate/GABA-synthesized enzymes, suggesting that HMGB1 signaling contributes to initiation of epileptic seizures.

Extracellular HMGB1 increases the intercellular glutamate concentration and MHCII expression levels

We examined whether extracellular HMGB1 increased intracellular/extracellular glutamate concentrations (Fig. 5A and B). Following incubation of PRNCs with $1 \mu \mathrm{g} / \mathrm{ml} \mathrm{HMGB1}$ for 3 days at $37^{\circ} \mathrm{C}$, intracellular glutamate concentration was significantly increased (Fig. $5 \mathrm{~A}$, $\mathrm{p}<0.05$ ). However, we could not detect any significant changes in extracellular glutamate concentration (Fig. 5B, $p=0.748$ ). Furthermore, we evaluated whether extracellular HMGB1 affected expression of MHC II (CD74 or OX6; invariant chain), which is a neuroinflammation marker [34, 35] sensitive to both exogenous and endogenous antigenic proteins [34]. We observed that MHC II expression levels were significantly increased (Fig. 5C, p < 0.05), indicating that exogenous HMGB1 accompanied the initiation of neural cell death processes.

\section{Discussion}

The present study demonstrated that KA treatment of PRNCs induced the translocation of HMGB1 from nucleus to cytosol, resulting in post-translational modifications. The KAinduced increment in extracellular HMGB1 was neurotoxic, decreasing PRNC cell viability and mitochondrial activity, downregulating GAD67 and GLUD1/2 expression, and increased intracellular glutamate and MHC II concentrations. These data suggest that HMGB1 participates in seizure initiation, which is a key pathophysiological feature of stage epilepsyrelated hyperexcitability.

Pathological analyses of patient brain tissues with refractory epilepsy indicate rampant neuroinflammatory processes. HMGB1, which acts like an inflammatory cytokine, is increased in epileptogenic human brain tissue and in chronic mice [12]. The considerable influence 
Fig. 5. Effects of KA and HMGB1 on intracellular/extracellular glutamate concentration and MHC II expression levels. PRNCs were incubated with $10 \mu \mathrm{M}$ KA (KA), $1 \mu \mathrm{g} / \mathrm{ml}$ HMGB1 (HMGB1), or in the absence of reagent (CONT) for 3 days at $37^{\circ} \mathrm{C}$. (A) Intracellular glutamate concentration. (B) Extracellular glutamate concentration. (C) Expression levels of MHC II in PRNCs. Experiments were independently conducted for $3 \sim 6$ times. $a$ vs $a \mathrm{p}<$ $0.05,{ }^{*} \mathrm{p}<0.05$, and ${ }^{* *} \mathrm{p}<0.01$.

of neuroinflammation in epilepsy implicates the involvement of excitable elements in brain disorder, in particular energy metabolism requiring metabolic control [36]. Along this line of investigations, KA excitotoxic animal model has been widely accepted as a model of epilepsy. Commonly used model of mesial temporal lobe epilepsy include acute systemic injection of KA [12, 20, 22]. We recently reported the utility of $\mathrm{KA}$ in resembling many of the pathological features of early stage epilepsyrelated hyperexcitability in cultured PRNCs [16]. P-glycoprotein (P-gp), a membrane-bound transporter [37], is associated with inflammatory process in the epileptic brain [38]. At $24 \mathrm{~h}$ after $\mathrm{KA}$ injection into the mouse hippocampus, nuclear-

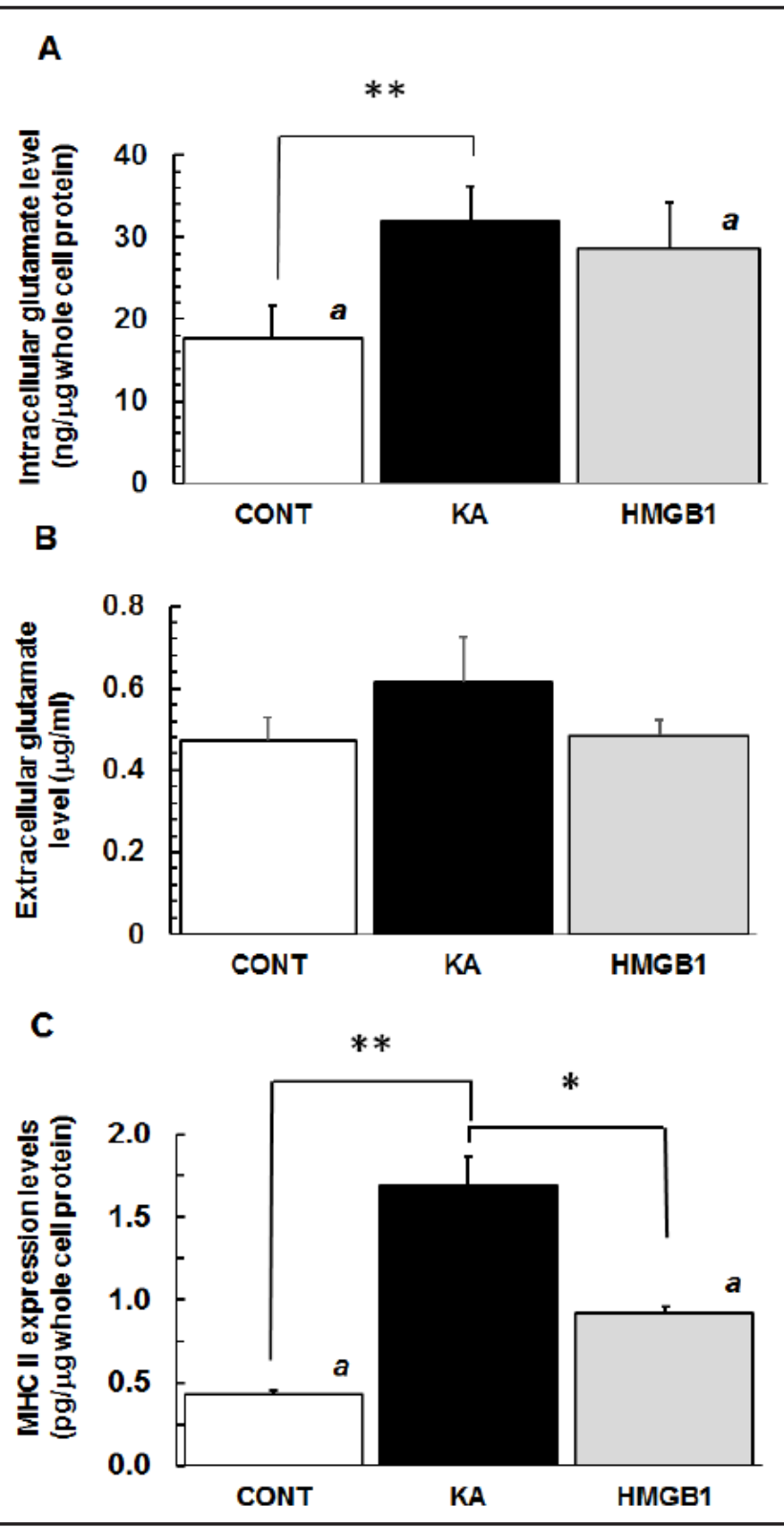
to-cytoplasmic translocation of HMGB1 ensues and closely accompanies the upregulated expression of P-gp in the post-seizure brain [39]. These data collectively indicate that KA-induced HMGB1 translocation is associated with a considerable neuroinflammatory response, which we showed here was characterized by MHC II upregulation.

Using this in vitro KA paradigm in the present study, we demonstrated HMGB1 translocation from nuclear to cytosol, and extracellular space (Fig. 1). The observation that HMGB1 was released from the damaged cells exposed to KA excitotoxicity offers novel post-translational modifications in the pathology of epilepsy-related hyperexcitability. KA induces Golgi-ER complex fragmentation/dispersal and shifts the proteolysis in PRNCs [23]. To date, KA interacting with HMGB1 remains unexplored, however, previous studies provide some clues on the possible participation of HMGB1 in cell function. HMGB1 is independently secreted through a Golgi-ER secretory pathway due to the lack of signal peptide [40]. It is transported from the nucleus to the cytoplasm and then into the lysosomes and ultimately released in to the extracellular space through exocytosis. HMGB1's accumulation in secretory lysosome suggests the involvement of $\mathrm{Ca}^{2+}$ regulated secretion [41]. Acetylation [42] and 
phosphorylation [43] of HMGB1 regulate its intracellular localization and extracellular secretion, reflecting its ability to function as an inflammatory mediator. In this study, HMGB1 was acetylated and phosphorylated by KA-administration (Fig. 2, right panel). These findings are consistent with previous studies demonstrating that inflammation- and cellular stressmediated acetylation of HMGB1 prevents its nuclear reentry and leads to the accumulation of HMGB1 in cytoplasm [44]. Interestingly, IP analysis (Fig. 2 right panel, red arrow) revealed that KA-induced HMGB1 mobility was approximately $8 \mathrm{kDa}$ shorter than Western blot analysis (Fig. 2 left panel, blue arrow) and indicated that HMGB1 is mono ubiquitinated. This mono ubiquitination regulates the target protein's cellular functions, such as membrane trafficking [45, 46] and exocytosis [47]. These results provide novel evidence that the shuttling of HMGB1 between the nucleus and extracellular space may be tightly regulated in response to an epileptogenic signal. A limitation of the study is the use of pan-modification markers to demonstrate acetylation, phosphorylation and ubiquitination of HMGB1. The observed positive bands may represent modified proteins that interact with HMGB1, based on the similarity of size and patterns of all three targets characterized as two bands around $35-40 \mathrm{kd}$, with a strong and a weak upper and lower band, respectively. Future studies using HMGB1 specific antibodies should reveal discrete levels of acetylated, phosphorylated, and ubiqitinated HMGB1.

Administering two different types of chemoconvulsants KA and bicuculline (a GABA $R$ antagonist) resulted in acute increases in HMGB1 at mouse hippocampus [12]. Constitutive exposure of HMGB1 is associated with chronic epilepsy in rat model and in human epileptic tissues [48]. Here, we showed KA and HMGB1 afforded comparable neurotoxic effects in decreasing PRNC cell viability (Fig. 3A). Our results (Fig. 3) concur with a previous report that the combined injection of KA and HMGB1 into mouse hippocampus significantly increases the seizure area compared with the effect produced by KA alone [12]. Of note, treatment with HMGB1 alone in the present study significantly dampened PRNC mitochondrial activity, comparable to the effect of KA alone (Fig. 3B and C). Mitochondria are the main producers of ATP needed for neuronal electrical activities and synaptic transmission. In the progression of epilepsy, mitochondrial dysfunction closely coexists with epileptogenesis and chronic epilepsy [49]. Altogether, these results suggest that a deficient ATP maintenance following HMGB1 exposure corresponds to the early stages of epilepsy-related hyperexcitability. Because the present study employed the mixed culture system, the observed cell viability and mitochondrial activity most likely reflected a mixed response of both cultured neurons and astrocytes. In order to reveal the specific proliferative and apoptotic activity of astrocytes separate from the neurons, additional experiments are using pure cell culture systems. Notwithstanding, that KA induces neuronal death and astrogliosis in vivo might have been reproduced here by our mixed culture system. In view of astrocytes being activated by HMGB1 and acquiring a reactive phenotype, which results in increased production of various chemokines and cytokines, this cell death-mediated effect alone might result in mortality of the cultured cells.

Extracellular glutamate is taken up by glutamate transporters and rapidly converted to the non-excitotoxic amino acid glutamine by GS in a process requiring ATP (Fig. 4A). In the brain, GS functions as an inhibitor of glutamate-dependent excitotoxicity [50]. Intracellular excessive glutamate is converted into GABA and/or $\alpha$-ketoglutarate by GAD65/67 and GLUD1/2, respectively (Fig. 4A). KA and HMGB1 significantly decreased the expression levels of GAD67 and GLUD1/2, but both reagents did not produce any pronounced effect on GAD65 (Fig. 4). GAD67 tightly binds the coenzyme pyridoxal 5-phosphate (PLP) and is constitutively active (holoenzyme form), robustly producing GABA in the brain [51,52]. In contrast, GAD65 depends on the interconversion between an active PLP-bound holoenzyme and an inactive apoenzyme [53], requiring the activation of extra GABA synthesis. Moreover, GAD67 is more ubiquitously distributed within neurons and associated with the synthesis of GABA released. PLP is a cofactor for GAD67 and its deficiency can induce neonatal epileptic encephalopathy [54]. Because GAD67 acts as the major catalyst of GABA production [51, 52], a deficit in GAD67-mediated GABA synthesis is likely to reduce the GABAergic inhibition

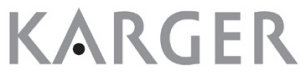




\section{Cellular Physiology Cell Physiol Biochem 2017;41:947-959

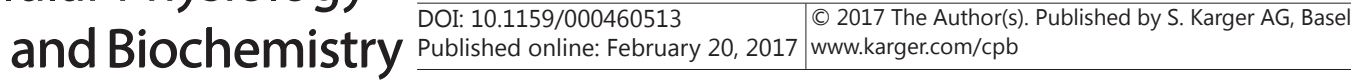 \\ Kaneko et al.: HMGB1 and Epilepsy-Like Hyperactivity}

in the brain. It is conceivable that under KA treatment, a synergistic effect of decreased GS expression (Fig. 4) and suppressed mitochondrial activity (Fig. 3B) in PRNCs may amplify neural cell death processes. This hypothesis is supported by the observation that KA and HMGB1 significantly increased intracellular glutamate concentration and upregulated MHC II expression (Fig. 5).

Our data revealed that KA induced an intracellular HMGB1 translocation that was exquisitely regulated by post-translation modifications, with extracellular HMGB1 shifting the glutamine/GABA equilibrium in PRNCs, capturing the early stages of epilepsy-related hyperexcitability initiation. We recognize the need to determine the downstream pathways (i.e. acetylation, phosphorylation, and ubiquitination) and to complement with in vivo studies this observed KA-HMGB1 in vitro interaction in order to strengthen the clinical relevance of the findings. Because epilepsy, is a network disease, there is limited direct translational application of the present cell culture paradigm, which represents an artificial system with a specific number of neural subtypes. Nonetheless, the present results advance the concept of HMGB1 post-translational modifications $[28,55]$, in our understanding of disease pathology and developing treatments for epilepsy-related hyperexcitability.

\section{Acknowledgments}

This work was supported by USF OR\&I HSC-18330 \& COM HSC-18300 (YK), NIH NINDS R01 1R01NS071956-01 (CVB), and USF Department of Neurosurgery and Brain Repair Funds (CVB). YK and CVB contributed to study design. YK, CP, NT, and CVB contributed to data acquisition. YK, CP, TM, FV, NT, and CVB wrote the manuscript.

\section{Disclosure Statement}

The authors state that they have no conflict of interest.

\section{References}

1 Cendes F: Epilepsy in 2011: Insights into epilepsy treatments and biomarkers. Nat Rev Neurol 2012;8:7071.

2 Yasuhara T, Agari T, Kameda M, Kondo A, Kuramoto S, Jing M, Sasaki T, Toyoshima A, Sasada S, Sato K, Shinko A, Wakamori T, Okuma Y, Miyoshi Y, Tajiri N, Borlongan CV, Date I: Regenerative medicine for epilepsy: from basic research to clinical application. Int J Mol Sci 2013;14:23390-23401.

- Lotze MT, Tracey KJ: High-mobility group box 1 protein (HMGB1): nuclear weapon in the immune arsenal. Nat Rev Immunol 2005;5:331-342.

4 Baxevanis AD, Landsman D: The HMG-1 box protein family: classification and functional relationships. Nucleic Acids Res 1995;23:1604-1613.

-5 Wang H, Bloom O, Zhang M, Vishnubhakat JM, Ombrellino M, Che J, Frazier A, Yang H, Ivanova S, Borovikova L, Manogue KR, Faist E, Abraham E, Andersson J, Andersson U, Molina PE, Abumrad NN, Sama A, Tracey KJ: HMG-1 as a late mediator of endotoxin lethality in mice. Science 1999;285:248-251.

6 Cheng Y, Wang H, Mao M, Liang C, Zhang Y, Yang D, Wei Z, Gao S, Hu B, Wang L, Cai Q: Escin Increases the Survival Rate of LPS-Induced Septic Mice Through Inhibition of HMGB1 Release from Macrophages. Cell Physiol Biochem 2015;36:1577-1586.

7 Kim JB, Sig Choi J, Yu YM, Nam K, Piao CS, Kim SW, Lee MH, Han PL, Park JS, Lee JK: HMGB1, a novel cytokine-like mediator linking acute neuronal death and delayed neuroinflammation in the postischemic brain. J Neurosci 2006;26:6413-6421.

-8 Liu J, Wu P, Wang H, Wang Y, Du Y, Cheng W, Xu Z, Zhou N, Wang L, Yang Z: Necroptosis Induced by AdHGF Activates Endogenous C-Kit+ Cardiac Stem Cells and Promotes Cardiomyocyte Proliferation and Angiogenesis in the Infarcted Aged Heart. Cell Physiol Biochem 2016;40:847-860. 


\section{Cellular Physiology Cell Physiol Biochem 2017;41:947-959

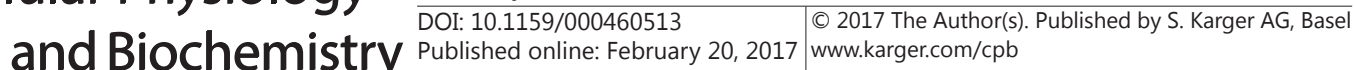 \\ Kaneko et al.: HMGB1 and Epilepsy-Like Hyperactivity}

-9i X, Hu X, Wang J, Xu W, Yi C, Ma R, Jiang H: Short-Term Hesperidin Pretreatment Attenuates Rat Myocardial Ischemia/Reperfusion Injury by Inhibiting High Mobility Group Box 1 Protein Expression via the PI3K/Akt Pathway. Cell Physiol Biochem 2016;39:1850-1862.

10 Wang J, Hu X, Xie J, Xu W, Jiang H: Beta-1-adrenergic receptors mediate Nrf2-HO-1-HMGB1 axis regulation to attenuate hypoxia/reoxygenation-induced cardiomyocytes injury in vitro. Cell Physiol Biochem 2015;35:767-777.

11 Okuma Y, Liu K, Wake H, Zhang J, Maruo T, Date I, Yoshino T, Ohtsuka A, Otani N, Tomura S, Shima K, Yamamoto Y, Yamamoto H, Takahashi HK, Mori S, Nishibori M: Anti-high mobility group box-1 antibody therapy for traumatic brain injury. Ann Neurol 2012;72:373-384.

$\checkmark 12$ Maroso M, Balosso S, Ravizza T, Liu J, Aronica E, Iyer AM, Rossetti C, Molteni M, Casalgrandi M, Manfredi AA, Bianchi ME, Vezzani A: Toll-like receptor 4 and high-mobility group box-1 are involved in ictogenesis and can be targeted to reduce seizures. Nat Med 2010;16:413-419.

-13 Sasaki T, Liu K, Agari T, Yasuhara T, Morimoto J, Okazaki M, Takeuchi H, Toyoshima A, Sasada S, Shinko A, Kondo A, Kameda M, Miyazaki I, Asanuma M, Borlongan CV, Nishibori M, Date I: Anti-high mobility group box 1 antibody exerts neuroprotection in a rat model of Parkinson's disease. Exp Neurol 2016;275 Pt 1:220-231.

14 Mazarati A, Maroso M, Iori V, Vezzani A, Carli M: High-mobility group box-1 impairs memory in mice through both toll-like receptor 4 and Receptor for Advanced Glycation End Products. Exp Neurol 2011;232:143-148.

15 Chen Z, Chen Y, Pan L, Li H, Tu J, Liu C, Dai X, Zhang X, Sun G, Feng D: Dachengqi Decoction Attenuates Inflammatory Response via Inhibiting HMGB1 Mediated NF-kappaB and P38 MAPK Signaling Pathways in Severe Acute Pancreatitis. Cell Physiol Biochem 2015;37:1379-1389.

16 Fang P, Schachner M, Shen YQ: HMGB1 in development and diseases of the central nervous system. Mol Neurobiol 2012;45:499-506.

17 Harris HE, Andersson U, Pisetsky DS: HMGB1: a multifunctional alarmin driving autoimmune and inflammatory disease. Nat Rev Rheumatol 2012;8:195-202.

18 Yang WS, Kim JS, Han NJ, Lee MJ, Park SK: Toll-like receptor 4/spleen tyrosine kinase complex in high glucose signal transduction of proximal tubular epithelial cells. Cell Physiol Biochem 2015;35:2309-2319.

19 Yang WS, Han NJ, Kim JJ, Lee MJ, Park SK: TNF-alpha Activates High-Mobility Group Box 1 - Toll-Like Receptor 4 Signaling Pathway in Human Aortic Endothelial Cells. Cell Physiol Biochem 2016;38:21392151.

20 Grabenstatter HL, Dudek FE: A new potential AED, carisbamate, substantially reduces spontaneous motor seizures in rats with kainate-induced epilepsy. Epilepsia 2008;49:1787-1794.

-21 Bialer M, White HS: Key factors in the discovery and development of new antiepileptic drugs. Nat Rev Drug Discov 2010;9:68-82.

22 Luo L, Jin Y, Kim ID, Lee JK: Glycyrrhizin suppresses HMGB1 inductions in the hippocampus and subsequent accumulation in serum of a kainic acid-induced seizure mouse model. Cell Mol Neurobiol 2014;34:987-997.

23 Kaneko Y, Sullivan R, Dailey T, Vale FL, Tajiri N, Borlongan CV: Kainic Acid-Induced Golgi Complex Fragmentation/Dispersal Shifts the Proteolysis of Reelin in Primary Rat Neuronal Cells: An In Vitro Model of Early Stage Epilepsy. Mol Neurobiol 2016;53:1874-1883.

24 Kaneko Y, Tajiri N, Shojo H, Borlongan CV: Oxygen-glucose-deprived rat primary neural cells exhibit DJ-1 translocation into healthy mitochondria: a potent stroke therapeutic target. CNS Neurosci Ther 2014;20:275-281.

25 Bell E, Cao X, Moibi JA, Greene SR, Young R, Trucco M, Gao Z, Matschinsky FM, Deng S, Markman JF, Naji A, Wolf BA: Rapamycin has a deleterious effect on MIN-6 cells and rat and human islets. Diabetes 2003;52:2731-2739.

26 Kaneko Y, Pappas C, Tajiri N, Borlongan CV: Oxytocin modulates GABAAR subunits to confer neuroprotection in stroke in vitro. Sci Rep 2016;6:35659.

27 Laemmli UK: Cleavage of structural proteins during the assembly of the head of bacteriophage T4. Nature 1970;227:680-685.

28 Hwang JS, Choi HS, Ham SA, Yoo T, Lee WJ, Paek KS, Seo HG: Deacetylation-mediated interaction of SIRT1HMGB1 improves survival in a mouse model of endotoxemia. Sci Rep 2015;5:15971. 


\section{Cellular Physiology Cell Physiol Biochem 2017;41:947-959 \begin{tabular}{cc|c|c|c|} 
DOI: 10.1159/000460513 & O 2017 The Author(s). Published by S. Karger AG, Basel \\
wwww.karger.com/cpb
\end{tabular} \\ Kaneko et al.: HMGB1 and Epilepsy-Like Hyperactivity}

29 Choi JS, Kim SY, Park HJ, Cha JH, Choi YS, Kang JE, Chung JW, Chun MH, Lee MY: Upregulation of gp130 and differential activation of STAT and p42/44 MAPK in the rat hippocampus following kainic acid-induced seizures. Brain Res Mol Brain Res 2003;119:10-18.

30 Youn JH, Shin JS: Nucleocytoplasmic shuttling of HMGB1 is regulated by phosphorylation that redirects it toward secretion. J Immunol 2006;177:7889-7897.

-31 Tang D, Kang R, Xiao W, Wang H, Calderwood SK, Xiao X: The anti-inflammatory effects of heat shock protein 72 involve inhibition of high-mobility-group box 1 release and proinflammatory function in macrophages. J Immunol 2007;179:1236-1244.

-32 Lu B, Antoine DJ, Kwan K, Lundback P, Wahamaa H, Schierbeck H, Robinson M, Van Zoelen MA, Yang H, Li J, Erlandsson-Harris H, Chavan SS, Wang H, Andersson U, Tracey KJ: JAK/STAT1 signaling promotes HMGB1 hyperacetylation and nuclear translocation. Proc Natl Acad Sci U S A 2014;111:3068-3073.

33 Yu Y, Tang D, Kang R: Oxidative stress-mediated HMGB1 biology. Front Physiol 2015;6:93.

34 VanGuilder HD, Bixler GV, Brucklacher RM, Farley JA, Yan H, Warrington JP, Sonntag WE, Freeman WM: Concurrent hippocampal induction of MHC II pathway components and glial activation with advanced aging is not correlated with cognitive impairment. J Neuroinflammation 2011;8:138.

-35 Acosta SA, Tajiri N, de la Pena I, Bastawrous M, Sanberg PR, Kaneko Y, Borlongan CV: Alpha-synuclein as a pathological link between chronic traumatic brain injury and Parkinson's disease. J Cell Physiol 2015;230:1024-1032.

-36 Sada N, Lee S, Katsu T, Otsuki T, Inoue T: Epilepsy treatment. Targeting LDH enzymes with a stiripentol analog to treat epilepsy. Science 2015;347:1362-1367.

-37 Bauer B, Hartz AM, Pekcec A, Toellner K, Miller DS, Potschka H: Seizure-induced up-regulation of P-glycoprotein at the blood-brain barrier through glutamate and cyclooxygenase-2 signaling. Mol Pharmacol 2008;73:1444-1453.

-38 van Vliet EA, van Schaik R, Edelbroek PM, Redeker S, Aronica E, Wadman WJ, Marchi N, Vezzani A, Gorter JA: Inhibition of the multidrug transporter P-glycoprotein improves seizure control in phenytoin-treated chronic epileptic rats. Epilepsia 2006;47:672-680.

-39 Chen Y, Huang XJ, Yu N, Xie Y, Zhang K, Wen F, Liu H, Di Q: HMGB1 Contributes to the Expression of P-Glycoprotein in Mouse Epileptic Brain through Toll-Like Receptor 4 and Receptor for Advanced Glycation End Products. PLoS One 2015;10:e0140918.

40 Bonaldi T, Talamo F, Scaffidi P, Ferrera D, Porto A, Bachi A, Rubartelli A, Agresti A, Bianchi ME: Monocytic cells hyperacetylate chromatin protein HMGB1 to redirect it towards secretion. EMBO J 2003;22:55515560 .

41 Gardella S, Andrei C, Ferrera D, Lotti LV, Torrisi MR, Bianchi ME, Rubartelli A: The nuclear protein HMGB1 is secreted by monocytes via a non-classical, vesicle-mediated secretory pathway. EMBO Rep 2002;3:9951001.

42 Dimov SI, Alexandrova EA, Beltchev BG: Differences between some properties of acetylated and nonacetylated forms of HMG1 protein. Biochem Biophys Res Commun 1990;166:819-826.

43 Kimura K, Katoh N, Sakurada K, Kubo S: Phosphorylation of high mobility group 1 protein by phospholipidsensitive Ca2+-dependent protein kinase from pig testis. Biochem J 1985;227:271-276.

-44 Evankovich J, Cho SW, Zhang R, Cardinal J, Dhupar R, Zhang L, Klune JR, Zlotnicki J, Billiar T, Tsung A: High mobility group box 1 release from hepatocytes during ischemia and reperfusion injury is mediated by decreased histone deacetylase activity. J Biol Chem 2010;285:39888-39897.

45 Liu Y, Li H, Sugiura Y, Han W, Gallardo G, Khvotchev M, Zhang Y, Kavalali ET, Sudhof TC, Lin W: UbiquitinSynaptobrevin Fusion Protein Causes Degeneration of Presynaptic Motor Terminals in Mice. J Neurosci 2015;35:11514-11531.

-46 Alexopoulou Z, Lang J, Perrett RM, Elschami M, Hurry ME, Kim HT, Mazaraki D, Szabo A, Kessler BM, Goldberg AL, Ansorge O, Fulga TA, Tofaris GK: Deubiquitinase Usp8 regulates alpha-synuclein clearance and modifies its toxicity in Lewy body disease. Proc Natl Acad Sci U S A 2016;113:E4688-4697.

47 Segref A, Hoppe T: Think locally: control of ubiquitin-dependent protein degradation in neurons. EMBO Rep 2009;10:44-50.

48 Kleen JK, Holmes GL: Taming TLR4 may ease seizures. Nat Med 2010;16:369-370.

49 Zsurka G, Kunz WS: Mitochondrial dysfunction and seizures: the neuronal energy crisis. Lancet Neurol 2015;14:956-966. 


\section{Cellular Physiology Cell Physiol Biochem 2017;41:947-959

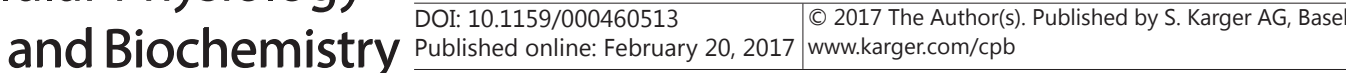 \\ Kaneko et al.: HMGB1 and Epilepsy-Like Hyperactivity}

50 Papageorgiou IE, Gabriel S, Fetani AF, Kann 0, Heinemann U: Redistribution of astrocytic glutamine synthetase in the hippocampus of chronic epileptic rats. Glia 2011;59:1706-1718.

51 Kash SF, Tecott LH, Hodge C, Baekkeskov S: Increased anxiety and altered responses to anxiolytics in mice deficient in the 65-kDa isoform of glutamic acid decarboxylase. Proc Natl Acad Sci USA 1999;96:1698-

1703.

52 Fenalti G, Law RH, Buckle AM, Langendorf C, Tuck K, Rosado CJ, Faux NG, Mahmood K, Hampe CS, Banga JP, Wilce M, Schmidberger J, Rossjohn J, El-Kabbani O, Pike RN, Smith AI, Mackay IR, Rowley MJ, Whisstock JC: GABA production by glutamic acid decarboxylase is regulated by a dynamic catalytic loop. Nat Struct Mol Biol 2007;14:280-286.

53 Kass I, Hoke DE, Costa MG, Reboul CF, Porebski BT, Cowieson NP, Leh H, Pennacchietti E, McCoey J, Kleifeld O, Borri Voltattorni C, Langley D, Roome B, Mackay IR, Christ D, Perahia D, Buckle M, Paiardini A, De Biase D, Buckle AM: Cofactor-dependent conformational heterogeneity of GAD65 and its role in autoimmunity and neurotransmitter homeostasis. Proc Natl Acad Sci USA 2014;111:E2524-2529.

54 Kuo MF, Wang HS: Pyridoxal phosphate-responsive epilepsy with resistance to pyridoxine. Pediatr Neurol 2002;26:146-147.

55 Min SW, Chen X, Tracy TE, Li Y, Zhou Y, Wang C, Shirakawa K, Minami SS, Defensor E, Mok SA, Sohn PD, Schilling B, Cong X, Ellerby L, Gibson BW, Johnson J, Krogan N, Shamloo M, Gestwicki J, Masliah E, Verdin E, Gan L: Critical role of acetylation in tau-mediated neurodegeneration and cognitive deficits. Nat Med 2015;21:1154-1162. 